\title{
A GESTÃO DE PESSOAS COMO ESTRATEGIA DE MAXIMIZAÇÃO DOS RESULTADOS DE UMA EMPRESA POR MEIO DA EQUIPE DE VENDAS
}

\author{
Geovana de Oliveira Pereira
}

Universidade do Oeste Paulista - UNOESTE, Gestão Comercial, Presidente Prudente, SP.

E-mail: ge o.p@outlook.com

\section{RESUMO}

A gestão de pessoas desenvolvida como uma estratégia de aumento de faturamento é uma tarefa complexa e desafiadora. A liderança estratégica cria condições favoráveis para esse processo, pois refere-se à obtenção de retornos acima da média e a criação de vantagens competitivas. Se desenvolvida por um líder com perfil transformacional, os resultados da liderança estratégica serão potencializados pela capacidade desse profissional em despertar o melhor da sua equipe, orientando as suas atitudes a curto prazo por uma visão no longo prazo. Assim sendo, o objetivo deste artigo foi demonstrar, por meio de estudos exploratórios e bibliográficos, que a gestão de pessoas, utilizada como estratégia, pode contribuir para maximizar o faturamento de uma empresa através da sua equipe de vendas. Os resultados permitiram que esse objetivo fosse atingido, tornando a premissa verdadeira em sua conclusão.

Palavras-chave: Gestão de Pessoas, Gestão Estratégica, Liderança Estratégica, Maximização de Resultados, Equipe de Vendas.

\section{MANAGEMENT OF PEOPLE AS A STRATEGY FOR MAXIMIZING THE RESULTS OF A COMPANY THROUGH THE SALES TEAM}

\begin{abstract}
Managing people developed as a billing enhancement strategy is a complex and challenging task. Strategic leadership creates favorable conditions for this process, as it refers to obtaining aboveaverage returns and creating competitive advantages. If developed by a leader with a transformational profile, the results of the strategic leadership will be enhanced by the ability of this professional to arouse the best of his team, guiding their short-term attitudes for a long-term vision. Therefore, the objective of this article was to demonstrate, through exploratory and bibliographic studies, that the people management, used as strategy, can contribute to maximize a company's sales through its sales team. The results allowed this objective to be achieved, making the premise true in its conclusion.
\end{abstract}

Keywords: People Management, Strategic Management, Strategic Leadership, Results Maximization, Sales Team.

\section{INTRODUÇÃO}

O presente trabalho aborda a temática da maximização de resultados através da gestão estratégica de uma equipe de vendas. Se na década de 1910, Taylor e Fayol possuíam uma visão mecanicista do trabalho humano, em 1927 a Teoria das Relações Humanas começou a mudar este pensamento. Stadler e Pampolini (2014) ponderam que a partir desta mudança, as organizações passaram a perceber o funcionário como um colaborador, um parceiro, e atribuem isto ao crescimento e à evolução do mercado e às novas tecnologias.

A importância das pessoas dentro das organizações passa a ser cada vez mais reconhecida, bem como a necessidade de investir-se neste capital. Esta importância é ressaltada por 
Chiavenato:

Hoje, [...] as diferenças individuais estão sendo realçadas e incentivadas, os talentos, estão sendo procurados com sofreguidão, e as competências pessoais, aprimoradas para garantir a competitividade organizacional. A diversidade está em alta. As pessoas estão deixando de ser meros recursos produtivos para ser o capital humano dentro da organização. [...] Cada qual apresenta conhecimentos, habilidades e competências que constituem aspectos importantes da vantagem competitiva da organização. (Chiavenato, 2014, p. 04).

Por conseguinte, o atual foco da sociedade nas relações humanas tornou-se fator de mudanças no modo de ver e gerenciar as pessoas dentro das empresas.

Milkovich e Boudreau (apud ROMERO, COSTA E SILVA, 2013, p.17) conceituam a gestão de pessoas como o "conjunto de decisões integradas sobre as relações de emprego que influenciam a eficácia dos colaboradores/servidores e das organizações".

Chiavenato (2014, p. 08) considera o conceito de gestão de pessoas instável e flexível.

[...] é uma área muito sensível à mentalidade e à cultura corporativa que predomina nas organizações. Ela é extremamente contingencial e situacional, pois depende de vários aspectos, como a arquitetura organizacional, a cultura corporativa, as características do seu mercado, o negócio da organização, a tecnologia utilizada, os processos internos, o estilo de gestão e uma infinidade de outras variáveis. Também depende das características das pessoas que a constituem. Tudo isso constitui um mix que a torna única em cada organização.

Stadler e Pampolini (2014, p. 21) abordam a importância das pessoas e de investir-se nelas:

Na era informacional (ou do conhecimento), o elemento humano deve ser considerado o maior patrimônio de uma organização, já que nenhum software, ferramenta, máquina, processo produtivo ou equipamento existe independentemente do recurso humano. As pessoas devem ser vistas como um patrimônio intangível, que precisa ser motivado, instigado, desenvolvido e reconhecido, para que sejam capazes de transformar o conhecimento que possuem em recursos tangíveis para a empresa, que, por sua vez, refletirá essa relação em contribuições relevantes para a sociedade.

Silva, Cravo e Teixeira (2016) afirmam que na década de 1980 surgiu a expressão "Gestão Estratégica de Pessoas", oriunda do reconhecimento da importância do capital humano, ressaltando as pessoas como fatores essenciais na conquista da vantagem competitiva e destacando a necessidade de alinhar-se a gestão de pessoas como a estratégia organizacional.

Para Chiavenato (2014, p. 11):

A estratégia organizacional constitui o mecanismo pelo qual a organização interage com seu contexto ambiental para realizar sua missão. A estratégia define o comportamento da organização em um mundo mutável, dinâmico e competitivo. É o único integrante racional e inteligente da estratégia organizacional é o elemento humano: a cabeça e o sistema nervoso da 
organização. O cérebro do negócio. A inteligência que tomas decisões acertadas.

Para a correta compreensão deste estudo, devemos ainda, entender que a liderança estratégica difere do termo liderança e é conceituada por Hitt, Ireland e Hoskisson (2011, p. 343) como "a capacidade de antecipar, vislumbrar, manter a flexibilidade e capacitar outros a promover mudanças estratégicas sempre que necessário". Este profissional busca gerar vantagem competitiva e retornos acima da média através de estratégias baseadas na visão e na missão da empresa.

Diante disto, o objetivo desta pesquisa é demonstrar que uma gestão de pessoas, em seu aspecto estratégico, pode contribuir para maximizar o faturamento de uma empresa através da sua equipe de vendas.

\section{METODOLOGIA}

A metodologia utilizada constou da técnica de estudos exploratórios e bibliográficos, visando abordar, conhecer, discutir e reforçar análises de pesquisas científicas bem como permitir novas discussões.Segundo Cervo, Bervian e da Silva (2007, p. 63)“A pesquisa exploratória realiza descrições precisas da situação e quer descobrir as relações existentes entre seus elementos componentes". Em um primeiro momento a pesquisadora utilizou-se desta pesquisa para aprofundar o seu conhecimento sobre o tema abordado e assim discutir com maior relevância os assuntos abordados.

Cervo, Bervian e da Silva (2007, p. 60) afirmam ainda que "A pesquisa bibliográfica procura explicar um problema a partir de referências teóricas publicadas em artigos, livros, dissertações e teses". Neste sentido a pesquisadora utilizou de todas as fontes disponíveis para alcançar o seu objetivo geral, os objetivos específicos e por fim dar uma resposta ao seu problema de pesquisa.

\section{RESULTADOS}

Diante da abrangência da temática da Gestão de Pessoas, identifica-se como uma das grandes problemáticas a interpretação limitada deste assunto. Gerir pessoas e administrar um capital intelectual de forma eficaz e lucrativa vai muito além de ser um bom chefe, ou, no contexto comercial, um chefe que aguenta cobrança e pressão.

Pensando nesta gestão de forma estratégica, é imprescindível abordar a liderança estratégica como uma potencial obtentora de resultados satisfatórios para a empresa, pois é uma forma de gestão focada em propósitos e grandes objetivos, geralmente elaborados de acordo com a visão e a missão da organização, onde cada etapa do processo de gerir passa a ter um por quê e um para quê. $O$ líder passa a ter que tomar decisões rápidas e assertivas em cenários muitas vezes conturbados, sem desviar o foco da sua estratégia à longo prazo, sendo ainda mais responsável pelos resultados da sua equipe.

No contexto comercial, esses aspectos são mais intensos, onde a pressão e as exigências por resultados são ainda maiores sobre quem está à frente da equipe de vendas, pois a mesma está diretamente ligada aos percentuais de faturamento da organização. E se essa equipe ou algum de seus integrantes não possui um bom desempenho significa que, em algum momento da gestão, o líder falhou, pois é ele o responsável pelo modo como cada processo será desenvolvido. Se o problema estiver no perfil profissional ou humano do vendedor, a falha continua sendo do líder e ocorreu na primeira etapa da gestão de pessoas, no processo de agregar (recrutamento e seleção), e perdurou pelos próximos, onde poderia ter sido trabalhada no processo de treinar e desenvolver pessoas.

Diante desta perspectiva, torna-se importante considerar a influência que o perfil de cada 
integrante da equipe de vendas exerce sobre a obtenção de resultados, e ainda mais importante compreender o papel do líder estratégico na equipe, considerando o seu próprio perfil de liderança.

Sendo assim, o estudo apresentado obteve como resultado que a liderança estratégica da equipe de vendas é uma potencial forma de maximizar os resultados de uma empresa, principalmente se for exercida por um líder com perfil transformacional. Bergamini (1994), embasada na Teoria de Bums, reforça esta idéia ao abordar as características motivadoras, orientadas para o alcance de resultados acima da média e dotadas de inteligência emocional deste líder que, através da sua empatia e capacidade de planejar o futuro de forma estratégica, consegue desenvolver a liderança em seus próprios liderados.

[...] está implícita a existência da grande sensibilidade com relação aos desejos e necessidades dos seguidores. Pela própria definição, o líder transformacional exemplifica com suas ações o verdadeiro modelo motivacional de relacionamento interpessoal. Supõe-se então que o líder eficaz conheça as autênticas necessidades dos seus seguidores, estando, assim, em condições de interferir com maior acerto ao facilitar a satisfação motivacional. A liderança transformacional propõe que a influência ocorra em dupla direção para que se estabeleça o clima de respeito ao outro enquanto pessoa integral. É da convivência com o seguidor que o líder retira a maior fonte de informações de que necessita para o exercício do seu papel [...]. Colocando-se praticamente no papel de parceiro do liderado, o líder não necessita de sua autoridade formal, o subordinado voluntariamente o segue pelo vínculo tipicamente afetivo que se estabelece entre os dois. (BERGAMINI, 1994, p. 110)

\section{DISCUSSÃO}

Como visto, o perfil do líder irá influenciar direta e profundamente a forma como a gestão de pessoas e a liderança estratégica serão desenvolvidas na equipe de vendas e, consequentemente, nos resultados desta equipe, pois influi não apenas o relacionamento com o grupo, mas a forma de entender, analisar e lidar com diferentes situações.

Dessa forma, autores como Silva (2003), Guerra (2001), Vergara (2000), Cury (2000), Maximiano (2000), Botelho e Krom (2010), Junior e Lipp (2011) e Chiavenato (2014), embasados em um estudo feito por White e Lippitt, apresentam três destes estilos, sendo eles, liderança autocrática, liderança liberal e liderança democrática.

A liderança autocrática enfatiza somente o líder, este é centralizador e dominador. Detém toda autoridade e as tomadas de decisões, emite ordens esperando que os subordinados as cumpram plena e cegamente.

Já a liderança liberal considera somente o coletivo. O líder possui um comportamento evasivo e sem firmeza, permite que as decisões sejam tomadas com total liberdade pelo grupo ou individualmente, só participando se for solicitado pelo grupo.

Por fim, há a liderança democrática, que apresenta o líder como um facilitador e um orientador do grupo, auxilia nas tomadas de decisões e na definição dos problemas e das soluções, sugere ideias e coordena as atividades. É um líder comunicativo e que estimula a participação de todos, pois preocupa-se tanto com o trabalho quanto com o grupo em si.

Ainda sobre os estudos de White e Lippitt, grupos foram submetidos aos três estilos de liderança citados e seus desempenhos foram analisados.

Os grupos submetidos ao estilo de liderança autocrática apresentaram o maior volume de trabalho produzido, entretanto, denotou-se sinais evidentes de tensão, frustração e agressividade. 
Na ausência do líder, os grupos interrompiam suas atividades e demonstravam seus altos níveis de insatisfação.

Já sobre os grupos submetidos ao estilo de liderança liberal, não foram obtidos bons resultados na quantidade e na qualidade do trabalho produzido. Apresentou-se ainda, fortes sinais de individualismo, insatisfação, agressividade, desagregação do grupo e pouco respeito ao líder.

Por fim, os grupos submetidos ao estilo de liderança democrática apresentaram boa quantidade e ainda melhor qualidade no trabalho produzido, aliados a um clima de satisfação, responsabilidade, integração grupal e comprometimento pessoal. Entretanto, se confrontado aos aspectos que a liderança estratégica exige, o democrático não apresenta, necessariamente, características indispensáveis para o desenvolvimento desta liderança, como uma visão com foco no futuro, capacidades voltadas para a vantagem competitiva e para retornos acima da média, entre outras.

Portanto, como já citado, o perfil de liderança transformacional é adotado por vários autores como o mais eficaz no desenvolvimento da liderança estratégica.

A liderança transformacional pode mudar a instituição, pois motiva os funcionários a fazerem mais do que se esperava que fizessem. Esse tipo de líder modifica a cultura do trabalho utilizando padrões de comportamento como carisma (popularidade), estimulação intelectual (criar nos outros uma consciência dos problemas e de suas soluções) e consideração individualizada (desenvolvimento e fortalecimento da equipe, de modo que as pessoas e a organização se beneficiem no final). (RIBEIRO, SANTOS E MEIRA, 2016, p. 112)

\section{CONCLUSÃO}

A discussão provocada reforça o intuito de demonstrar a gestão de pessoas como um processo estratégico e um potencial propulsor dos resultados da empresa. Esta percepção implica em considerar o gestor como um líder estratégico e propõe uma análise crítica dos leitores sobre o modo como cada processo da gestão de pessoas pode ser explorado e desenvolvido através dessa nova perspectiva. Esse líder cria a sua estratégia embasada na missão e na visão da organização em que atua, objetivando maximizar resultados e criar vantagem competitiva. Quando a liderança estratégica é desenvolvida por um profissional com perfil transformacional, os retornos são ainda mais satisfatórios. Isso ocorre porque o líder que possui esse perfil, por ser dotado de inteligência emocional, transforma a realidade estressante e de intensa cobrança da área comercial em um ambiente de comum união e motivação, onde apresenta-se como um exemplo para a sua equipe, despertando um real compromisso de cada um com os objetivos organizacionais, reduzindo aspectos como o tempo de execução de tarefas, custos e esforços desnecessários, e aumentando, significativamente, o faturamento da empresa. Tudo isso ocorre porque estas duas dimensões, liderança estratégica e perfil transformacional, potencializam o sucesso a curto e a longo prazo da equipe de vendas.

Não obstante, torna-se importante reforçar que o perfil de liderança transformacional é considerado pela literatura como o mais eficaz no desenvolvimento da liderança estratégica e assim o foi apresentado neste estudo, mas por si só, a liderança estratégica já apresenta-se como uma forma de gestão da equipe de vendas de alto potencial na maximização dos resultados de uma empresa, podendo também obter sucesso através de outros perfis de liderança.

\section{REFERÊNCIAS BIBLIOGRÁFICAS}

BERGAMINI, C. W. LIDERANÇA: A administração do sentido. Revista de Administração de Empresas, São Paulo, v. 34, n. 3, p. 102-114, 1994. Disponível em:

http://www.scielo.br/pdf/rae/v34n3/a09v34n3.pdf. Acesso em: 17 de maio de 2017. 
Botelho, J.C. \& Krom, V. (2011). Os estilos de liderança nas organizações. XIV Encontro Latino Americano de Iniciação Científica e X Encontro Latino Americano de Pós-Graduação - Universidade do Vale do Paraíba.

CERVO, A. L.; BERVIAN, P. A.; DA SILVA, R. Metodologia Científica. 6. ed. São Paulo: Pearson Prentice Hall, 2007. Disponível em:

http://unoeste.bv3.digitalpages.com.br/users/publications/9788576050476/pages/61. Acesso em: 01 fevereiro de 2017.

CHIAVENATO, Idalberto. Administração nos novos tempos: os novos horizontes em administração. 3. ed. Barueri, SP: Manole, 2014.

CURY, A. Organização e métodos: uma visão holística. 7. ed. São Paulo: Atlas, 2000.

GUERRA, E. Influência dos estilos gerenciais no clima organizacional. Dissertação de mestrado não publicada, Escola de Administração Pública, Fundação Getúlio Vargas, Rio de Janeiro, 2001.

HITT, M. A.; IRELAND, R. D.; HOSKISSON, R. E. Administração estratégica: competitividade e globalização. Tradução All Tasks 2a ed. São Paulo: Cengage Learning, 2011.

JUNIOR, E.; LIPP, M. Estilo de Liderança e Stress: Uma pesquisa em escolas estaduais de ensino fundamental, RBPAE. nํ.02,p265-283,2011.

MAXIMIANO, A. C. A. Introdução à administração. 5. ed. São Paulo: Atlas, 2000.

RIBEIRO M.; SANTOS S.L.; Meira T.G.B.M. Refletindo sobre liderança em enfermagem. Esc Anna Nery Rev Enferm. 2006;10(1):109-15.

ROMERO, S. M. T.; COSTA, S. F.; SILVA, L. M. K. Gestão de Pessoas: conceitos e estratégias. Curitiba: InterSaberes, $2013 . \quad$ Disponível em: http://unoeste.bv3.digitalpages.com.br/users/publications/9788582127001 Acesso em: 05 de março de 2017.

SILVA, A. L.; CRAVO, J. R.; TEIXEIRA, T. F.; A GESTÃO ESTRATÉGICA DE PESSOAS COMO FATOR PRINCIPAL DE DESENVOLVIMENTO HUMANO E EMPRESARIAL: estudo de caso da empresa Áurea Alimentos. Revista Maiêutica, v. 4, n. 1, p. 111-120, 2016.Disponível em: https://publicacao.uniasselvi.com.br/index.php/GESTAO_EaD/article/view/1588/717. Acesso em: 05 de março de 2017.

SILVA, J. A. Psicologia \& Comportamento. Ribeirão Preto: Canavaci, 2003.

STADLER, A.; PAMPOLINI, C. P. G. Gestão de Pessoas: ferramentas estratégicas de competitividade.(Coleção Gestão Empresarial;v.8)Curitiba: InterSaberes, 2014. Disponível em: http://unoeste.bv3.digitalpages.com.br/users/publications/9788544300572. Acesso em: 04 março de 2017.

VERGARA, S. C. Gestão de pessoas. São Paulo: Atlas, 2000. 